\title{
The CARE heuristic for addressing burnout in nurses
}

\author{
Jane Compson * \\ School of Interdisciplinary Arts and Sciences, University of Washington Tacoma, Tacoma, United States
}

Received: February 10, 2015

Accepted: April 7, 2015

Online Published: April 27, 2015

DOI: $10.5430 /$ jnep.v5n7p63

URL: http://dx.doi.org/10.5430/jnep.v5n7p63

\begin{abstract}
This paper provides a heuristic for addressing the pressing problem of burnout in nurses. Following a literature review about the causes and symptoms of burnout, a case will be made that the problem is best addressed from a variety of perspectives using different modalities. These are summarized under the different headings of Compassion, Awareness, Resilient Responding and Empowerment which together from the CARE heuristic. An explanation and justification for each of these different approaches is provided, along with practical exercises that nurses might practice in order to build capacity in each of these domains and protect themselves against or treat existing symptoms of burnout.
\end{abstract}

Key Words: Burnout, Compassion fatigue, Moral distress, Resilience, Compassion, Mindfulness, Awareness, Empowerment

\section{INTRODUCTION AND BACKGROUND}

\subsection{Burnout in nursing and the need to address it}

Studies have shown that most health professionals ${ }^{[1]}$ and specifically nurses ${ }^{[2]}$ have significantly elevated levels of burnout. Burnout contributes to high rates of job attrition and a shortage of registered nurses. ${ }^{[3]}$ Aiken et al. ${ }^{[2]}$ found that nurses in the US have an incidence of burnout that is $40 \%$ higher than the already elevated levels in health professionals generally, and that the level of job dissatisfaction among nurses is four times worse than in the average US worker. Nurse distress burdens more than just the nurses, but adds distress and burden to patients and the health care organization. Burnout in health professionals is positively correlated with suboptimal patient care ${ }^{[4]}$ and negatively correlated with patient satisfaction, ${ }^{[5]}$ suggesting that providers' burnout impacts not only their own career and personal well-being, but healthcare systems' effectiveness, customer satisfaction, and financial reimbursements when they are tied to these. In short, burnout is problematic for various reasons; it is subjectively unpleasant, results in suffering not only for the subject but for their patients, families and colleagues, and it is costly. Interventions and training to protect against and mitigate causes and symptoms of burnout are therefore urgently needed in the nursing profession. Various strategies have proven to be effective, some involving multiple sessions and others involving short practices, like daily writing. ${ }^{[6]}$ There are also other stress-reduction and positive psychology strategies that, while not yet studied specifically in the context of burnout, may prove beneficial in this context. In this research, many of these strategies have been reviewed and grouped into categories that form the basis of a heuristic called CARE. CARE is an acronym that stands for Compassion, Awareness, Resilient Responding, and Empowerment. This article gives a definition of burnout, describes the CARE heuristic, and offers arguments for why the CARE heuristic offers a helpful framework for tackling burnout. It provides an explanation of the rationale for the four categories of Compassion, Awareness, Resilient Responding and Empowerment, the kind of practices within these categories, and how they address burnout. A case is made for why these practices are

\footnotetext{
* Correspondence: Jane Compson; Email: jcompson@uw.edu; Address: School of Interdisciplinary Arts and Sciences, University of Washington Tacoma, 1900 Commerce Street, Tacoma, United States.
} 
better together. The CARE heuristic is then used as a framework for a CARE intervention - an example of an accessible program of exercises that nurses can use to ameliorate and protect against burnout.

\subsection{What is burnout?}

Burnout is a response to chronic stress in the work place, and has three dimensions - exhaustion, cynicism and inefficacy. ${ }^{[7]}$ Exhaustion refers to the sense of one's emotional and physical resources being depleted. ${ }^{[8]}$ Cynicism often manifests as depersonalization and describes the way that burnout appears in interpersonal context. Somebody experiencing this aspect of burnout may become very distant, treating others with excessive detachment and appearing negative or callous. Inefficacy refers to the individual's self-evaluation. He or she may feel unable to accomplish anything meaningful or significant in their work, and/or may doubt their own competence. A cause of and a response to this condition can be a phenomenon described as moral distress, which describes the experience where somebody feels expected to act in a way that is inconsistent with their own moral values. ${ }^{[9,10]}$

Burnout is caused by a mismatch between an individual and their job in one, some, or all of six worklife areas: workload, control, reward, community, fairness and values ${ }^{[11]}$ (see Table 1). The greater the mismatch in these areas, the greater the level of burnout. Conversely, the greater the perceived congruence between the person and the six worklife areas, the less likely they are to experience symptoms of burnout. Table 1 describes how burnout manifests in each of the six areas of worklife. Figure 1 depicts a theoretical model of burnout and its relation to areas of worklife. It is important to note that causes of burnout are both "internal" and "external". In other words, conditions might be such that a nurse is underpaid and overworked. It might also be the case that a nurse's psychological and emotional resources are stretched such that she or he is unable to cope with conditions that used to be manageable. A robust burnout intervention will address both dimensions of this. It will include problembased strategies focus on addressing "external" stressors, such as workplace hostility or overwork. It will also include emotion-based strategies which focus on the how the individual responds to external stressors and offer training in how to respond in a more functional way that leads to less distress. The CARE heuristic offers a structure that ensures both kinds of strategies are made available.

\subsection{Compassion fatigue and moral distress as contribu- tors to burnout}

Two phenomena falling under this category of values mismatch which are particularly relevant to nursing are compassion fatigue and moral distress. Protocols to ameliorate burnout should therefore address these issues, which will now be briefly explained.

\subsubsection{Compassion fatigue}

The term compassion fatigue (CF) was first coined by Figley in $1995^{[12]}$ and describes "the natural consequent behaviors and emotions resulting from knowing about a traumatizing event experienced or suffered by a person". CF is also described as secondary traumatic stress. Compassion fatigue could be understood as a sub-category of burnout, insofar as it represents a mismatch between the emotional resources required for compassionate response, and the demands on a caregiver for that response: "Energy expenditure outstrips restorative process." [13] Compassion fatigue is characterized as the a state of psychic exhaustion ${ }^{[14]}$ often caused by an empathetic response to the suffering of the patient and a feeling of guilt, helplessness, futility or self-blame accompanying cumulative grief and/or a perception of being unable to alleviate the patient's suffering. Valent hypothesized that part of this distress comes from an implicit appraisal in helpers that they must save or rescue the person suffering - a maladaptive psychological strategy he labels Rescue-Caretaking. ${ }^{[15]}$ When helpers are unable to "rescue" others, then they experience feelings of failure and self-blame, culminating in symptoms of compassion fatigue. Helpers exhibiting selfsacrificing behaviors may be at increased risk for compassion fatigue. ${ }^{[16]}$ The "values mismatch" occurs, then, when a caregiver feels compelled to help alleviate a patient's suffering, but feels ineffective or impotent to do so. Although it may be triggered by "external" factors compassion fatigue arises within the relational field between a nurse and the patient or their family ${ }^{[14]}$ and is a more emotion-based or "internal" manifestation of distress. The "flip-side" of compassion fatigue is compassion satisfaction. This occurs when there is a congruence of a caregiver's compassionate desire to alleviate the suffering of others, and the sense that they are succeeding in doing so. ${ }^{[17]}$

\subsubsection{Moral distress}

Moral distress describes the discomfort experienced in relation to ethical conflicts, when one is unable to translate one's moral choices into moral action. ${ }^{[19]}$ If compassion fatigue can generally be described as a symptom of distress emerging from the "internal" or emotion-based field, then moral distress is more typically (though not always) the result of "external" circumstances. For example, a cause of moral distress could be the expectation (derived from institutional policy) to provide invasive and medically futile interventions to a terminally ill patient. This may create a moral conflict where the nurse is engaging in activities (e.g., CPR) that they do not believe are in the patient's best interests, and thwart their compassionate intention to alleviate suffering. 
Table 1. Association between six areas of worklife and the burnout/engagement continuum

\begin{tabular}{|c|c|c|}
\hline Area of Worklife & Burnout & Engagement \\
\hline Workload & Work demands exceed perceived capacity to meet them & Workload is perceived as manageable. \\
\hline Control & $\begin{array}{l}\text { Sense of insufficient control/lack of autonomy to fulfill } \\
\text { responsibilities expected }\end{array}$ & $\begin{array}{l}\text { Sense of correspondence between control } \\
\text { and accountability. }\end{array}$ \\
\hline Reward & $\begin{array}{l}\text { Sense of not being recognized or valued socially, financially } \\
\text { and/or no sense of the work being intrinsically rewarding. }\end{array}$ & $\begin{array}{l}\text { Sense that contributions are valued and } \\
\text { acknowledged. }\end{array}$ \\
\hline Community & No sense of positive connection with people at work & $\begin{array}{l}\text { Sense that social environment is } \\
\text { supportive, collaborative and positive. }\end{array}$ \\
\hline Fairness & $\begin{array}{l}\text { Sense of inequitable treatment and not being valued and/or } \\
\text { respected }\end{array}$ & $\begin{array}{l}\text { Consistent and equitable rules for } \\
\text { everyone, applied with transparency. }\end{array}$ \\
\hline Values & $\begin{array}{l}\text { Sense that personal values are not shared by the organization, } \\
\text { and/or the individual feels compelled to act in ways incongruent } \\
\text { with their personal values (example: moral distress) }\end{array}$ & $\begin{array}{l}\text { Organizational and personal values are } \\
\text { perceived as congruent, and successes are } \\
\text { shared. }\end{array}$ \\
\hline
\end{tabular}

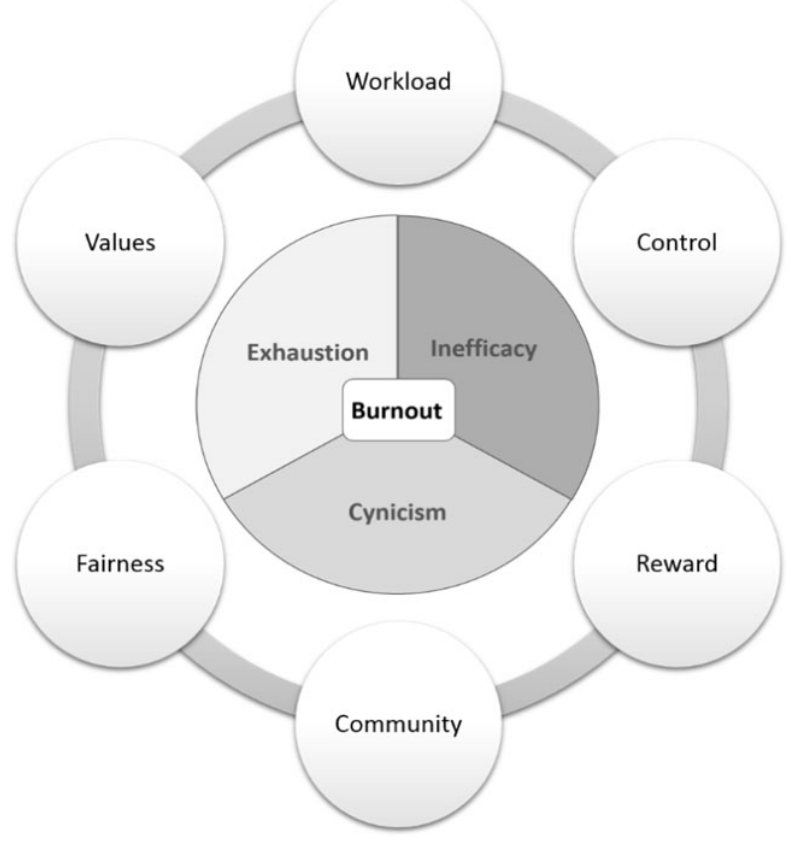

Figure 1. Burnout and areas of worklife theoretical model

\subsection{Which existing interventions exist to address burnout?}

Henry ${ }^{[6]}$ reviewed various burnout interventions for nurses. She compared ten different interventions described in research ranging from 2003 to 2010 . The interventions varied in format, length and content. For example, some included on-site sessions and retreats, while others offered off-site and even residential (i.e., overnight) interventions. Intervention modalities varied significantly and included reflective writing workshops, ${ }^{[18]}$ an eight-week mindfulness-based stress reduction program, ${ }^{[19]}$ and off-site team-building activities. ${ }^{[20]}$ In her review of studies of these burnout interventions, Henry found that they all showed positive outcomes, but that this was measured only by participant comments rather than more objective measurement tools. She notes there is a dearth of systematic research about the relative efficacy of different kinds of interventions to address burnout. However, there is evidence to suggest that an array of methods may be effective, and that burnout can be successfully addressed. Henry concludes that "nurses may decrease or prevent burnout by practicing self-care and encouraging treatment centers to support burnout intervention programs.",[6]

\section{THE CARE HEURISTIC}

The CARE heurisitic offers a systematic framework for structuring burnout interventions. It works by looking at the different components that lead to burnout, and then offering evidence-based practices to address these factors, grouped into four categories.

The CARE heuristic offers four kinds of domains for addressing burnout to be engaged synergistically. The hypothesis is that a systemic approach to ameliorating burnout will be more effective than applying just one kind of modality. For example, a focus only on emotion-based coping strategies may fail to address external, systemic problems that continually create stressful conditions that increase the likelihood of burnout. Conversely, a focus only on external conditions without addressing individual patterns of response may be equally ineffective, since studies have shown that even nurses with excellent working conditions and reporting good job satisfaction can still suffer burnout from the nature of their work. ${ }^{[21]}$ A multifaceted approach helps to avoid pitfalls or blind-spots that a single-pointed approach might be vulnerable to; it also offers flexibility and appeals to different temperaments and learning styles. For example, a psychological coping strategy such as "debriefing" that does not take account of the neurobiology of trauma and traumatic activation may, in the long run, cause more harm than good. ${ }^{[22,23]}$ A focus on empathetic resonance with another's suffering 
may lead to over-identification or "compassion fatigue" if it is not tempered by exercises that support relaxation and well-being. Structures with greater support are more stable. Another important point about the CARE heuristic is that each element works in concert with the others, providing four foundations that support psychological health and well-being, addressing the causes and symptoms of burnout. Although the four components of compassion, awareness, resilient responding and empowerment are listed in separate categories, they should be understood as being interdependent and mutually-reinforcing. The inclusion of these components in the heuristic is based on existing research about effectiveness of different interventions in addressing the symptoms of burnout.

\subsection{Compassion}

Compassion refers to the ability to "open to the reality of suffering and aspire to its healing". [24] While empathy involves the vicarious experiencing of another's emotions, and sympathy a fellow-feeling or kinship with another, compassion consists not only of the recognition of suffering, but the motivation to act to alleviate it. ${ }^{[25]}$ Since nursing is a profession devoted to caring for others, compassion is of course a key and indispensable virtue. Compassion is often at the root of many nurses' motivation to enter the profession, is "nursing's most precious asset", ${ }^{[25]}$ and "a powerful support in the realization of excellent nursing care." ${ }^{[26] ~ I m p o r t a n t l y, ~}$ compassion can be taught and and increased through the use of various practices. ${ }^{[27]}$ Compassion can be directed towards others and towards oneself.

Compassion is listed first in the CARE heuristic because it is foundational. Healthcare professionals taking steps to alleviate burnout are making an intentional and proactive move towards recognizing and reducing their own suffering, which is necessarily a compassionate act. Consciously acknowledging this act of self-compassion is an initial and important step towards a fuller development of compassionate practice, and a positive step that counters the sense of personal inefficacy and cynicism associated with burnout. Acknowledging this sets the intentional and affective tone for the rest of the work, rooting and reconnecting the practitioner with a core value that initially drew them to the profession.

This is important because one of the areas of mismatch associated with burnout is the realm of values. This may manifest as sense that one's personal values are not shared by the organization one works for, or that one is required to act in ways that are not congruent with one's personal values. Compassion training may be a powerful tool in addressing both of these difficulties, in ways briefly outlined below.
Research suggests that training in self-compassion provides the foundation for increased compassion for others. Selfcompassion describes viewing one's own experience through the eyes of a compassionate "other", recognizing how we share vulnerability to suffering with other people (and nonhuman beings), and creating a broadening and softening in our perspective. ${ }^{[27]}$ Self-compassion training is positively associated with happiness, optimism and positive affect, and negatively associated with psychopathology. ${ }^{[28,29]}$ Self-compassion is an important predictor of psychological health $^{[30]}$ and orients the individual towards social approach and social support, which in turn are factors that contribute to greater resilience. ${ }^{[27,31-33]}$ Higher self-compassion is associated with less reactivity to negative events, a greater tendency to put things in perspective, and also to take responsibility for one's own actions. ${ }^{[34]}$ Self-compassion practices enhance motivation and are negatively associated with pathological perfectionism. ${ }^{[35]}$ Self-compassion is also associated with an increased likelihood of sticking to a regimen of healthpromoting behaviors, such as fitness plans. ${ }^{[36]}$ This is significant, as one study showed that while nurses recognize that they engage in unhealthy behaviors, they demonstrated no strategies for changing them. ${ }^{[37]}$ Self-compassion is also associated with improved interpersonal functioning. ${ }^{[38]}$

These findings suggest that self-compassion training is indicated as a powerful potential tool to address burnout. Insofar as it builds personal positive affect and is associated with reduced symptoms of psychopathology, it addresses the exhaustion associated with burnout by increasing personal emotional resources and by encouraging engagement in activities that further support positive psychological health. Increased self-forgiveness, motivation and social approach help to counter the effects of depersonalization accompanying burnout, promoting a turning towards rather than away from others. The move away from pathological perfectionism may also help to counteract the sense of reduced personal efficacy and cynicism. These practices may have particular salience in relation to addressing compassion fatigue since one of the causes (and symptoms) of this is a sense of self-blame and self-criticism at the perception of being unable to alleviate patient suffering. Self-compassion practices may also be effective in modifying self-sacrificing behavior associated with "rescue-caretaking" where in addition to blaming themselves for not "rescuing" those who they care for, carers ignore or discount their own suffering. For example, one study on internal residents showed that those with the highest level of burnout are most likely to view their own needs as "inconsequential". [4] One of the characteristics of self-compassion is acknowledging and turning towards one's own suffering with an attitude of openness, acceptance and solidarity with 
others, so it may help to counteract self-sacrificing behaviors.

Self-compassion may also be helpful in addressing moral distress. This may seem counter-intuitive initially, as moral distress is often the result of is "external stressors", which emotion-based strategies like self-compassion by themselves may be of limited effectiveness in addressing. However, research on self-compassion training suggests that creating a more resilient and stable emotional state provides a more stable platform from which to engage in problem-based coping strategies. Shantz (2007) describes this effect of compassion as "morally empowering" (p.53). In other words, it can help to support problem-based coping, as well as being a powerful emotion-based coping strategy.

None of this would be helpful if compassion were just a personal characteristic that one either has or does not have and which cannot be developed through training. However, there is copious evidence that compassion can increase with training ${ }^{[27,39]}$ and that this in turn leads to increased compassion towards others. Being compassionate towards others is obviously desireable in the profession of nursing, benefitting not just patients but other employees. Being treated with compassion in the workplace creates an increased sense of belonging and being meaningfully connected with one's work, ${ }^{[40]}$ counteracting the sense of cynicism associated with burnout. Training to increase compassion consists of various kinds of exercise, ranging from short guided meditations to writing exercises to short activities, such as small intentional acts of generosity of kindness. Such exercises have already been shown in research to be effective in increasing compassion for self and others. ${ }^{[27]}$

It seems plausible that in some cases, compassion training might in fact heighten experiences of moral distress, by bringing into greater relief the contrast between compassionate intention and constraints on its realization. In such cases, problem-based (as opposed to emotion-based) strategies may be indicated as more appropriate tools to address some of the external conditions generating distress. These will be discussed in the Empowerment section. The point here is that compassion training should not be seen as a panacea that removes distress and the imperative to effect local or systemic change in unethical policies or practices. However, it does provide opportunities to increase resilience and psychological resources, strengthening the foundation from which to take appropriate action.

\section{Example compassion practices}

Exercises for developing compassion for self and others range from meditation practices such as loving kindness meditation to behavioral activities such as practicing acts of kindness $^{[41]}$ or cognitive exercises such as compassionate letter writing. ${ }^{[42]}$ More involved training programs are available, such as the eight-week or five-day intensive Mindful Self-Compassion program ${ }^{[43]}$ or Compassion-Focused Therapy, ${ }^{[44]}$ but these require a greater time-commitment. Many of the the exercises offered as part of these programs, particularly guided meditations, are available online and through apps.

\subsection{Awareness}

The term "awareness" can have various connotations. For the purposes of the CARE heuristic for addressing burnout, three aspects of awareness will be considered: awareness as knowledge about available options and resources; awareness of what is happening, including external events (situational awareness) and inner experience (self-awareness); mindful awareness.

\subsubsection{Awareness as knowledge of available resources and options}

In order to address problems that have been identified, it is important to know both which tools and resources are at one's disposal, and also which one(s) will likely be the most effective. ${ }^{[45]}$ Nurses at risk of burnout should be informed about the syndrome, know how to recognize the signs and symptoms, have sufficient self-awareness to recognize if they are showing signs of these symptoms, and also to be aware of the resources and techniques at their disposal for addressing burnout.

\subsubsection{Awareness as recognition of what is happening, both in terms of situational and self-awareness}

The first step in problem-solving is, of course, being aware of the problem in the first place. This most basic level of awareness requires sufficient reflective skills to recognize problematic stimuli. Awareness is thus highlighted in the CARE heuristic because the first step towards ameliorating difficult situations is to recognize them: "this ability to introspect and understand yourself is critical for coping with burnout. The first step in knowing what action to take is to know what you are feeling and why."[46]

Self-awareness is particularly important in the context of addressing burnout, because one of the strategies that nurses sometimes use to protect themselves against distressing stimuli is to use "distancing" as a coping strategy. ${ }^{[45]}$ Distancing means removing oneself from the painful stimuli, and can occur on either an inter-personal level (staying away from people or relationships that are difficult) or intra-personal (avoiding thoughts and emotions that are troubling and difficult). This can contribute to the depersonalization associated with burnout. One may become so removed from one's emotional experience that one many not even recognize the 
danger signs of burnout. This abilty to be self-aware requires skills of reflection and introspection.

\subsubsection{Mindfulness}

The development of mindfulness is a way of actualizing and strengthening both of the previous kinds of awareness. Mindfulness also brings with it many additional benefits that support psychological and physical health. It is thus a key component of the CARE heuristic. Mindfulness is a multifaceted construct, but for the purposes of this intervention it is understood as a non-judgmental and non-reactive awareness of what is happening in the present moment with an attitude of acceptance rather than aversion. ${ }^{[47,48]}$ Mindful awareness implies a certain level of equanimity and calm around this recognition, such that one is not paralyzed by reactivity. There are hundreds of studies supporting the efficacy of mindfulness practices in stress-reduction, ${ }^{[49]}$ including its effectiveness in reducing symptoms of emotional exhaustion and burnout among health professionals. ${ }^{[50-52]}$ Self-awareness and mindfulness are significantly positively correlated. ${ }^{[53]}$ Mindfulness training is associated with more than just increased self-awareness. It is also associated with self-regulation (an improved ability to moderate one's behavior) and self-transcendence, which describes a process of becoming more positively disposed towards others and being more pro-social. ${ }^{[54]}$

Authors of a meta-analysis of empirical studies of mindfulness training in healthcare professionals ${ }^{[50]}$ found that increased levels of mindfulness were associated with reduced stress and increased empathy; ${ }^{[55]}$ significant decreases in symptoms of burnout, and increases in relaxation and life satisfaction; ${ }^{[52]}$ increased positive affect and selfcompassion, and decreased state and trait anxiety and ruminative thoughts. ${ }^{[56]}$ Mindfulness and self-awareness are also positively correlated with emotional intelligence. Emotional intelligence can be broadly described as the ability to recognize, understand and regulate emotions in oneself. ${ }^{[57]}$ Greater mindfulness is associated with greater emotional intelligence, which in turn is associated with higher levels of positive affect, lower negative affect, increased life satisfaction ${ }^{[58]}$ and increased self-compassion. ${ }^{[59]}$ Mindfulness training seems to have a synergistic relationship with self-compassion, with some researchers proposing that self-compassion is a key mechanism by which mindfulness-based stress reduction programs increase well-being. ${ }^{[27]}$ Many of these studies are associated with the completion of an 8-week Mindfulness Based Stress Reduction (MBSR) course; this could be problematic because this course requires a fairly significant time commitment (a weekly 3 hour face-to-face class and up to 45 minutes of daily "homework"). However, some studies suggest that less extensive mindfulness training is still effective. An abbreviated web-based mindfulness-based stress reduction course (reducing the time commitment to $25 \%$ of the standard MBSR course) was correlated with improved resilience, physical, cognitive and emotional vigor and was associated with significant decreases in perceived stress and burnout in participants. ${ }^{[60]}$ A different study on an abbreviated (weekend-long) mindfulness training for primary care clinicians found that participants had significantly better scores on all the subscales of the Maslach burnout inventory, even nine months after the intervention. ${ }^{[61]}$

Mindfulness training, then, is indicated as an effective tool, not only to develop situational and self-awareness, but for the other concomitant benefits that have been shown to lead to positive change in all the sub domains of burnout.

\subsubsection{Examples of mindfulness exercises}

Mindfulness has soared in popularity in recent years, and there is a plethora of easily accessible brief mindfulness training exercises. These range from formal sitting practices (such as mindfulness of breathing or the mindful body scan), to exercises that can be undertaken during the course of everyday activities, such as the RAIN exercise (recognition, acceptance, investigation and non-identification) or mindful walking. More formal or systematized training is offered by programs such as Mindfulness-Based Stress Reduction or abbreviated programs as mentioned above.

\subsection{Responding resiliently}

The verb "to respond" can have the connotation of a positive or appropriate reaction to a stimulus, and it is this connotation that is emphasized in the CARE heuristic. "Responding" can be contrasted to "reacting", where reacting involves habitual, instinctive and unconscious processes, and "responding" refers to more considered and conscious processes. Sometimes it is strong neurobiological reactions that account for this difference - when we are faced with stimuli we perceive as traumatic or threatening then our sympathetic nervous system becomes very activated, putting us into "fight, flight or freeze" mode. In this state of activation our ability to think clearly and rationally can be compromised. We are predisposed to react instinctively rather than respond calmly and rationally; we are only able to do the latter when we have restored a state of greater equilibrium between the parasympathetic and sympathetic nervous systems. At other times, even when we are not in crisis, it may be force of habit, or lack of awareness of alternative options, that lead us into unhelpful reactive patterns. Responding is emphasized in the CARE heuristic because the moment between stimulus and response or reaction is one where interventions and training can make a difference. It is the territory where interventions to address burnout must operate, an area of great potential. 
Interventions to mitigate burnout should seek to transform patterns of negative reactivity into resilient responses.

\subsubsection{Resilience}

Resilience describes the ability to maintain wellbeing and function positively in the face of stress and adversity, ${ }^{[62,63]}$ rather than being unable to cope. Research into resilient individuals helps to identify some of the habits and practices that support well-being and flourishing, and suggests that such methods can be learned. ${ }^{[33,63,64]}$ Studies in resilience indicate that certain specific cognitive strategies, behavioral habits and meditative exercises can help people to respond to potentially upsetting events in ways that are protective of their psychological well-being. ${ }^{[32]}$ Specifically, supportive mentoring relationships, maintaining positivity, developing emotional insight, achieving life balance and spirituality, and becoming more reflective are all strategies associated with increased personal resilience. ${ }^{[63]}$ While compassion and awareness training both contribute to resilience, this part of the heuristic builds on these foundations and brings to the forefront many of the insights of positive psychology. Put simply, one of the ways of responding to negative emotions is to focus on positive ones - emotions that engender joy and happiness. Even brief "uplifts" (experiences that bring joy or happiness) can help to foster resilience and ameliorate work stress in nurses. ${ }^{[65]}$ Studies in positive psychology have found ways of achieving these "uplifts" through brief exercises that require very little time commitment. ${ }^{[66-68]}$ Self-administered positive or happiness activities, including counting one's blessings, visualizing and writing about one's ideal future self, and cultivating one's strengths work by "mimicking the myriad healthy thoughts and behaviors associated with naturally happy people". ${ }^{69]}$ Research in Fredrickson's "broaden and build" theory demonstrates that the cultivation of positive emotions helps distressed people recover from stressful events more quickly, and broadens their repertoire of intellectual,physical and social resources to support their wellbeing, which in turn builds their resiliency and well-being, creating a positive upward spiral. ${ }^{[70,71]}$ The development of such resources may help to inoculate against the exhaustion and cynicism associated with burnout, increasing personal capacity to cope with workload demands and strengthening a positive sense of community.

\subsubsection{Examples of resilience exercises}

Keeping a gratitude diary, where one writes down five things for which one is grateful, leads to increases in positive affect, decreases in negative affect, and builds friendships and social bonds. ${ }^{[72]}$

Visualizing and writing about one's best possible self is associated with a reduction in negative affect and an increase in

Published by Sciedu Press positive affect, deepening emotional resilience. ${ }^{[73]}$

Performing conscious acts of altruism. Performing acts of kindness decreases stress and leads to improvments in mental health. ${ }^{[74]}$ Lyubomirsky found that participants in a study who committed to performing five daily acts of kindness a day reported greater happiness for many days after the experiment. ${ }^{[75]}$

\subsubsection{Trauma resiliency - Understanding neurobiology}

Having at least a basic understanding of the neurobiology of stress and trauma is an important part of responding resiliently to hardship. In particular, one of the most important things to be aware of is the power of the flight, fight or freeze response to override the activities of the most recently evolved part of the brain that supports regulation of our thoughts, actions and emotion (the prefrontal cortex). ${ }^{[76]}$ Expecting somebody to "rationalize" or "think through" their response when they are in such a state is asking them to do something of which they are, at least temporarily, neurologically incapable. To restore equilibrium and the better functioning of the prefrontal cortex, the balance between the sympathetic and parasympathetic nervous system needs to be restored, and this can be achieved through sensory or somatic techniques such as focusing on neutral or pleasant sensory sensations (including mindfulness exercises). It is also important to acknowledge that previous traumatic episodes can be suddenly and unexpectedly reactivated by apparently innocuous triggers (such as smells, sounds and so on) and send a person into a state of sympathetic nervous system hyperarousal that severely limits their ability to function. Nurses are exposed to high-stress and potentially traumatic situations with great frequency in their line of work. Awareness of how trauma can manifest physically and psychologically, as well as techniques to cope with times of traumatic activation should thus be an indispensable part of resiliency training.

\subsubsection{Example exercises for engendering resilient re- sponses to trauma}

More formal training in the neurobiology of trauma and techniques for calming the nervous system provided by brief interventions such as the Community Resiliency Model have been shown to decrease distress symptoms and increase wellbeing. [77]

Expressive writing for just a few minutes a day about a traumatic event leads to boosts in psychological and physical health, and enhanced social role functioning according to various studies. ${ }^{[78]}$

The G.R.A.C.E. intervention, ${ }^{[79]}$ designed for clinicians, is an example of a brief training that builds compassion and resilience. This relatively brief (11 contact hour) training helps 
to address compassion deficit by priming qualities that support the emergence of compassion, such as attention, affect, insight, intentionality and somatic sensitivity. Techniques for developing thes properties are grouped around the acronym G.R.A.C.E., which stands for "Gathering Attention; Recalling Intention; Attuning to Self and Other; Considering what will serve; Engaging, enacting, ending".

\subsection{Empowerment}

A sense of reduced personal efficacy is a key component of burnout. ${ }^{[80]}$ In terms of the six areas of worklife this particularly manifests in the domain of control, which includes the employee's perception of their capacity to exert professional autonomy, to have access to resources to do their job effectively, to influence decisions affecting their work, and to shape the work environment into one consistent with their personal values. ${ }^{[81]}$

A negative perception in these regards leads to a sense of inefficacy or disempowerment, which are correlated with burnout. Conversely, more engagement or job satisfaction is reported when employees feel that they are able to participate in decision-making in their organization and have the power and control to effectively do their job in a manner congruent with their personal values. Another element affecting the sense of efficacy is social support and teamwork.

Interventions to protect against and ameliorate symptoms of burnout should contain elements to help foster an increased sense of personal efficacy in these domains. In the CARE heuristic the word empowerment is used as the umbrella term for these elements as they are intended not just to foster an increased sense of personal efficacy but also to address external difficulties or structural constraints which disempower nurses in their ability to fulfill their role in a meaningful way consistent with their aspirations and values. Many of the exercises in the categories already described will help to foster this intrapersonal sense of empowerment by increasing available emotional and psychological resources, offering better selfcare skills and practices and so on. However, it is important to look at the systemic factors that contribute to burnout, and not put all the emphasis on the coping skills of the individual practitioner. It is often the case external factors such as workplace demands, working conditions, interpersonal and institutional dynamics, and/or scarcity of support services contribute to highly stressful situations for employees. A study by Li et al. about the relationshiop between nursing burnout and these "ecological pressures" in multiple countries found that environmental conditions make pronounced contributions to burnout in nurses. While interventions to help employees manage stress and improve resiliency are important, they should not be used to deflect attention from structural, external pressures. Li et al. recommend that "hospital-wide and unit-specific interventions should be considered to achieve excellent work environments." ${ }^{[82]}$ The CARE heuristic advocates a systems approach to addressing burnout, recognizing that an atomistic focus on the individual rather than on the context in which they are operating would be a limited and incomplete approach to addressing the problem, especially if the causes of it are systemic. In other words, steps should be taken to avoid pathologizing individual responses without addressing dysfunctions in the wider system that create these stressful conditions. An example to illustrate this point is the issue of moral distress. A recent literature review of twenty articles about the concept of moral distress in nursing found that while there were different nuances about its meaning and causes, almost all drew on the original definition by Jameton that "moral distress arises when one knows the right thing to do, but institutional constraints make it nearly impossible to pursue the right course of action." ${ }^{[83]}$ Most of the articles found the effects of moral distress to be negative, leading to burnout, resignation and high work turnover. Sources of such moral distress were clustered into the following groups:

- Clinical situations (e.g., futile or aggressive treatment that harms the patient; inadequate pain management).

- Difficult working conditions and resource limitations (e.g., corporatization of healthcare; longer working hours, organizational policies).

- Structural conditions (e.g., asymmetries of power and authority; undervaluing of the role of nurses; devaluing of nurse perspectives; inability to advocate; poor team work).

- Moral sources (e.g., value conflicts between professional expectations and personal moral compass).

With the possible exception of the last group (although professional expectations are a systemic issue), these sources are basically in the systemic or institutional arena, rather than in the arena of subjective responding (although of course they may lead to distress in this domain). They are most appropriately addressed, then, in this arena by strategies that are problem-based rather than just emotion-based. A summary of strategies to reduce moral distress in nursing literature $^{[84]}$ reflects this focus, with suggestions for actions such as developing policies to encourage education, interdisciplinary cooperation and and open discussion about moral distress; building support networks; creating opportunities to speak up, and implementing specific approaches such as the 4A's approach (Ask, affirm, assess, act) developed by the American Association of Critical Care Nurses. ${ }^{[85]}$ 


\section{Exercises and strategies for developing empowerment}

Insofar as they lead to increased health and well-being, improved positive affect, better physical health, and thus greater resilience, the exercises in the previous categories can be expected to have an empowering effect by providing stronger and broader personal emotional and psychological resources to draw on, increasing the ability to cope with challenging situations.

Exercises in this category are intended to address the cynicism and depersonalization associated with burnout and many of these are connected with a sense of diminished professional autonomy or a sense that the workplace at odds with one's own values. Strategies to counteract these effects, then, should address these issues on a systems-wide or institutional level, not just an intra-personal one. For example, a strategy for coping with moral distress is the 4 A's approach previously mentioned. Other strategies that have proved to be effective in alleviating burnout include employee assistance programs and on-site support services, interventions such as seminars, workshops and retreats, creating a supportive community in the workplace which encourage employees the opportunity to voice their feelings, opening or improving lines of communication between management and employees, and between different disciplines on a team. ${ }^{[6]}$

\section{DISCUSSION}

The CARE heuristic brings together findings from a broad spectrum of research and groups them into focused categories of interventions to address burnout. Burnout is multi- dimensional, and the hypothesis is that these different dimensions and sub-domains are more effectively addressed using a systemic, multi-faceted approach rather than just focusing on one kind of intervention. The CARE heuristic offers a framework for structuring interventions to address burnout. There are almost limitless ways in which such an intervention could be configured. Depending on the circumstances such as need, timing and available resources, training in each category could be a multi-week or even multi-year program, or a short-term intervention that is delivered over the course of a few hours. Depending on the conditions in which burnout is manifesting, the program could focus more on one component than another. Below is a brief suggested iteration of a CARE intervention.

\section{Furture RESEARCH: A CARE INTER- VENTION}

The CARE heuristic offers suggestions about the kind of practices and strategies that are useful in addressing burnout. Figure 2 offers a proposed curriculum for an intervention to address burnout, the CARE intervention. There are multiple ways that an intervention including the four elements of the CARE heuristic could be configured and provided the following is just an example for explanatory purposes. This proposed model is yet to be empirically tested, but it is hypothesized that nurses who complete this program would demonstrate reduced burnout scores on the Maslach Burnout Inventory. This study is planned as part of a future research project with nurses.

\begin{tabular}{|c|c|c|c|c|c|}
\hline & $\begin{array}{l}\text { Week 1: } \\
\text { Compassion }\end{array}$ & Week 2: Awareness & $\begin{array}{l}\text { Week 3: Resilient } \\
\text { Responding }\end{array}$ & $\begin{array}{l}\text { Week 4: } \\
\text { Empowerment }\end{array}$ & $\begin{array}{l}\text { Week 5: } \\
\text { Sustaining Change }\end{array}$ \\
\hline $\begin{array}{l}\text { Group meeting }-1 \\
\text { hour }\end{array}$ & \multicolumn{4}{|c|}{$\begin{array}{l}\text { Introduction to component, its rationale, and associated resources. } \\
\text { Introduce and practice 'homework' exercises. }\end{array}$} & $\begin{array}{l}\text { Planning personal } \\
\text { regimen; discussion of } \\
\text { ways of building social } \\
\text { and institutional support. }\end{array}$ \\
\hline $\begin{array}{l}\text { Homework: daily } \\
\text { practices, supported } \\
\text { by web platform. }\end{array}$ & & & & & \\
\hline $\begin{array}{l}\text { Formal practice } \\
(10-15 \text { minutes } \\
\text { daily })\end{array}$ & $\begin{array}{l}\text { Self-compassion } \\
\text { meditation (10 } \\
\text { minutes daily) }\end{array}$ & $\begin{array}{l}\text { Mindfulness of } \\
\text { breathing or body. }\end{array}$ & $\begin{array}{l}\text { 'Grounding and } \\
\text { resourcing' (Trauma } \\
\text { Resource Institute) } \\
\text { meditation. }\end{array}$ & $\begin{array}{l}\text { Strengths } \\
\text { exercise. }\end{array}$ & \multirow{3}{*}{$\begin{array}{l}\text { Exercise from one } \\
\text { category daily (subject's } \\
\text { choice) }\end{array}$} \\
\hline $\begin{array}{l}\text { Writing Activity } \\
(10-15 \text { minutes } \\
\text { daily })\end{array}$ & $\begin{array}{l}\text { Self-compassion } \\
\text { letter. }\end{array}$ & $\begin{array}{l}\text { Mindful journaling - } \\
\text { "What am I feeling } \\
\text { right now?" }\end{array}$ & $\begin{array}{l}\text { Expressive writing } \\
\text { about difficult event }\end{array}$ & $\begin{array}{l}\text { Complete a } \\
\text { gratitude diary }\end{array}$ & \\
\hline $\begin{array}{l}\text { Momentary } \\
\text { exercises (1 minute } \\
\text { or less, during the } \\
\text { course of one's } \\
\text { regular activities) }\end{array}$ & $\begin{array}{l}\text { Self-compassion } \\
\text { break }\end{array}$ & $\begin{array}{l}\text { RAIN (recognition, } \\
\text { acceptance, } \\
\text { investigation, } \\
\text { non-identification). }\end{array}$ & $\begin{array}{l}\text { Appreciating the } \\
\text { positive. }\end{array}$ & $\begin{array}{l}\text { Positive psych } \\
\text { exercise }\end{array}$ & \\
\hline
\end{tabular}

Figure 2. Table showing outline of curriculum for a proposed intervention based on the CARE heuristic 
The intervention would require five face-to-face group training sessions once a week of one hour with a facilitator. In each of the first four weeks participants would be introduced to one element of the CARE heuristic and taught how to practice the related exercises. They would then be assigned a daily "homework" for that week. Each homework will consist of a daily formal mediation or visualization practice of up to 15 minutes, and a writing practice of 10-15 minutes. Participants would also be taught "momentary" exercises (i.e., activities that take only a few moments to perform) that they can practice in the course of their everyday life. A web-based platform would support participants, providing information and resources, videos or audio files of guided practices, and a forum for communicating with the facilitator and other participants. By the end of four weeks, the participants will have had some practice with all four elements of the CARE heuristic. In the group session for the fifth week, the facilitator will help them to plan a personal regimen for the future, depending on the needs, experiences and preferences of the participant. It might be, for example, that one participant rotates through the different kinds of practice, while another focuses primarily on one of them. The fifth group meeting will also be dedicated to problem-solving and creating opportunities to build social and institutional support to assist empowerment.

A future study of this or another intervention based on the CARE heuristic would need to investigate the effectiveness of the intervention with pre- and post-test measures, such as the Maslach Burnout Inventory - Human Services Survey (MBI-HSS) and its companion, the Areas of Worklife Survey (AWS). Another possible area for future research would be comparing a relatively short-term training like the one suggested here with a more involved and longer-term training program in terms both of its feasibility and effectiveness in reducing symptoms of burnout.

\section{CONFLiCtS OF INTEREST Disclosure}

The author declares that there is no conflict of interest statement.

\section{REFERENCES}

[1] Wieclaw J, Agerbo E, Mortensen PB, et al. Risk of affective and stress related disorders among employees in human service professions. Occupational Environmental Medicine. 2006; 63(5): 314-9. PMid:16621851 http://dx.doi.org/10.1136/oem. 200 4.019398

[2] Aiken LH, Clarke SP, Sloane DM, et al. Hospital nurse staffing and patient mortality, nurse burnout, and job dissatisfaction. JAMA: the Journal of the American Medical Association. 2002; 288(16): 23-30 http://dx.doi.org/10.1001/jama.288.16.1987

[3] MacKusick CI, Minick P. Why are nurses leaving? findings from an initial qualitative study on nursing attrition. MEDSURG Nursing 2010; 19(6): 335-40. PMid:21337990

[4] Shanafelt TD, Bradley KA, Wipf JE, et al. Burnout and selfreported patient care in an internal medicine residency program. Annals of Internal Medicine. 2002; 136(5): 358-67. http://dx.doi.org/10.7326/0003-4819-136-5-200203050-00008

[5] Vahey DC, Aiken LH, Sloane DM, et al. Nurse burnout and patient satisfaction. Medical Care. 2004; 42(2): 57-66. http://dx.doi.o $\mathrm{rg} / 10.1097 / 01 . \mathrm{mlr} .0000109126 .50398 .5 \mathrm{a}$

[6] Henry BJ. Nursing burnout interventions. Clinical Journal of Oncology Nursing. 2014; 18(2): 211-4. PMid:24675256 http://dx.doi.org/10.1188/14.CJON.211-214

[7] Maslach C, Schaufeli WB, Leiter MP. Job Burnut. Annual Review of Psychology. 2001; 52(1): 397-422. PMid:11148311 http: //dx.doi.org/10.1146/annurev.psych.52.1.397

[8] Kowalski C, Ommen O, Driller E, et al. Burnout in nurses - the relationship between social capital in hospitals and emotional exhaustion. Journal of Clinical Nursing. 2010; 19(11-2): 1654-63.

[9] Rushton $\mathrm{CH}$. Defining and addressing moral distress: Tools for critical care nursing leaders. Advanced Critical Care. 2006; 17(2): 161-8. http://dx.doi.org/10.1097/00044067-200604000-00011
[10] Ferrell BR. Understanding the moral distress of nurses witnessing medically futile care. Oncology Nursing Forum. 2006; 33(5): 922-30. PMid:16955120 http://dx.doi.org/10.1188/06.0NF.922-9 30

[11] Leiter MP, Maslach C. Areas of worklife survey manual. Wolfville, NS: Center for Organizational Research and Development. 2006.

[12] Figley CR. Compassion fatigue: Coping with secondary traumatic stress disorder in those who treat the traumatized. New York \& London: Brunner Routledge; 1995.

[13] Coetzee SK, Klopper HC. Compassion fatigue within nursing practice: A concept analysis. Nurs Health Sci. 2010; 12(2): 23543. PMid:20602697 http://dx.doi.org/10.1111/j.1442-2 $018.2010 .00526 . x$

[14] Boyle D. Countering compassion fatigue: A requisite nursing agenda. The Online Journal of Issues in Nursing. 2011; 16(1). PMid:21800933

[15] Valent P. Diagnosis and treatment of helper stresses, traumas, and illnesses. In Figley C, (Ed). Treating Compassion Fatigue. New York: Brunner Routledge. 2002: 17-37.

[16] Abendroth M, Flannery J. Predicting the risk of compassion fatigue: A study of hospice nurses. Journal of Hospice \& Palliative Nursing. 2006; 8(6): 346-56. http://dx . doi .org/10.1097/00129191-2 00611000-00007

[17] Stamm BH. Measuring compassion satisfaction as well as fatigue: Developmental history of the compassion satisfaction and fatigue test. In Figley C, (Ed). Treating Compassion Fatigue. New York: Brunner Routledge; 2002: 107-119.

[18] Adams K, Putrino J. Expressive Writing to Promote Health Care. Interactive Podium Presentation at the 11th Annual Oncology Nursing Society Institutes of Learning, Orlando, FL; 2010.

[19] Cohen-Katz J, Wiley SD, Capuano T, et al. The effects of mindfulness-based stress reduction on nurse stress and burnout, part II: A quantitative and qualitative study. Holistic Nursing Practice. 
2005 Jan-Feb; 19(1): 26-35. PMid:15736727 http://dx.doi.org /10.1097/00004650-200501000-00008

[20] Lambert N, Steward N. Staff retreat: a journey to team building. In: 32nd Annual Oncology Nursing Society Congress; October 2011.

[21] Hayes B, Douglas C, Bonner A. Work environment, job satisfaction, stress and burnout among haemodialysis nurses. Journal of Nursing Management. 2013. PMid:24372699 http://dx.doi.org/10.11 $11 /$ jonm. 12184

[22] Mayou RA, Ehlers A, Hobbs M. Psychological debriefing for road traffic accident victims. three-year follow-up of a randomised controlled trial. British Journal of Psychiatry. 2000 Jun; 176: 58993. PMid:10974967 http://dx.doi.org/10.1192/bjp.176.6 .589

[23] Paterson HM, Whittle K, Kemp RI. Detrimental effects of postincident debriefing on memory and psychological responses. Journal of Police and Criminal Psychology. 2015; 30(1): 1-11. http: //dx.doi.org/10.1007/s11896-014-9141-6

[24] Feldman C, Kuyken W. Compassion in the landscape of suffering. Contemporary Buddhism. 2011; 12(1): 143-55. http://dx.doi.org/10.1080/14639947.2011.564831

[25] Schantz ML. Compassion: a concept analysis. Nursing forum. 2007; 42(2): 48-55. PMid:17474937 http://dx.doi.org/10.1111/j $.1744-6198.2007 .00067 . x$

[26] Van der CM. Compassion: The missing link in quality of care. Nurse Education Today. 2014; 34(9): 1253-7. PMid:24856582 http://dx.doi.org/10.1016/j.nedt.2014.04.003

[27] Germer CK. Self-compassion in clinical practice. Journal of Clinical Psychology. 2013; 69(8): 856-67. PMid:23775511 http://dx.doi .org/10.1002/jclp. 22021

[28] Barnard LK, Curry JF. Self-compassion: Conceptualizations, correlates, \& interventions. Review of general psychology. 2011; 15(4): 289-303. http://dx.doi.org/10.1037/a0025754

[29] Neff KD, Vonk R. Self-compassion versus global self-esteem: Two different ways of relating to oneself. Journal of Personality. 2009; 77(1): 23-50. PMid:19076996 http://dx.doi.org/10.1111/j $.1467-6494.2008 .00537 . x$

[30] Van Dam NT, Sheppard SC, Forsyth JP, et al. Self-compassion is a better predictor than mindfulness of symptom severity and quality of life in mixed anxiety and depression. Journal of Anxiety Disorders. 2011 1; 25(1): 123-30.

[31] Heaphy ED, Dutton JE. Positive social interactions and the human body at work: Linking organizations and physiology. Academy of Management Review Academy of Management Review. 2008; 33(1): 137-62. http://dx.doi.org/10.5465/AMR . 2008. 27749365

[32] Bonanno GA. Loss, trauma, and human resilience: Have we underestimated the human capacity to thrive after extremely aversive events? American Psychology. 2004; 59(1): 20-8. PMid:14736317 http://dx.doi.org/10.1037/0003-066X.59.1.20

[33] Denz-Penhey HMC. Personal resiliency: Serious diagnosis and prognosis with unexpected quality outcomes. Qualitative Health Research. 2008; 18(3): 391-404. PMid:18235162 http://dx.doi.org/10. $1177 / 1049732307313431$

[34] Leary MR, Tate EB, Adams CE, et al. Self-compassion and reactions to unpleasant self-relevant events: The implications of treating oneself kindly. Journal of Personality and Social Psychology. 2007; 92(5): 887-904. PMid:17484611 http://dx.doi.org/10.1037/00223514.92.5.887

[35] Neff KD. The development and validation of a scale to measure self-compassion. Self and identity. 2003; 2(3): 223-50. http: //dx.doi.org/10.1080/15298860309027

[36] Magnus CM, Kowalski KC, McHugh TF. The role of self-compassion in women's self-determined motives to exercise and exercise-related outcomes. Self and Identity. 2010; 9(4): 363-82. http://dx. doi.o $\mathrm{rg} / 10.1080 / 15298860903135073$

[37] Persson M, Mårtensson J. Situations influencing habits in diet and exercise among nurses working night shift. Journal of Nursing Management. 2006; 14(5): 414-23. PMid:16787477 http://dx.doi.o $\mathrm{rg} / 10.1111 / \mathrm{j} .1365-2934.2006 .00601 . \mathrm{x}$

[38] Neff KD, Beretvas SN. The role of self-compassion in romantic relationships. Self and Identity. 2013; 12(1): 78-98. http://dx. doi.o $\mathrm{rg} / 10.1080 / 15298868.2011 .639548$

[39] Jazaieri H, McGonigal K, Jinpa T, et al. A randomized controlled trial of compassion cultivation training: Effects on mindfulness, affect, and emotion regulation. Motivation and Emotion. 2014; 38(1): 23-35. http://dx.doi.org/10.1007/s11031-013-9368-z

[40] Truss C, Alfes K, Delbridge R, et al. Employee engagement in theory and practice. London and New York: Routledge; 2013.

[41] Lyubomirsky S. The how of happiness: A scientific approach to getting the life you want. New York: Penguin; 2008. PMid:18633666

[42] Gilbert P. The compassionate mind: A new approach to life's challenges. Oakland, CA: New Harbinger Publications; 2010.

[43] Germer CK. Mindful Self-Compassion. 2015. Avaible from: http: //www . mindfulself compassion. org

[44] Gilbert P. Introducing compassion-focused therapy. Advances in Psychiatric Treatment. 2009; 15(3): 199-208. http://dx.doi.org/1 0.1192/apt.bp.107.005264

[45] Blomberg K, Sahlberg-Blom E. Closeness and distance: A way of handling difficult situations in daily care. Journal of Clinical Nursing. 2007; 16(2): 244-54. PMid:17239059 http://dx.doi.org/1 $0.1111 / j .1365-2702.2005 .01503 . x$

[46] Maslach C. Burnout: The cost of caring. Los Altos, CA: ISHK; 2003.

[47] Hollis-Walker L, Colosimo K. Mindfulness, self-compassion, and happiness in non-meditators: A theoretical and empirical examination. Personality and Individual Differences. 2011; 50(2): 222-7. http://dx.doi.org/10.1016/j.paid.2010.09.033

[48] Feldman C, Kuyken W. Compassion in the landscape of suffering. Contemporary Buddhism. 2011; 12(1): 143-55. http://dx.doi.o $\mathrm{rg} / 10.1080 / 14639947.2011 .564831$

[49] Grossman P, Niemann L, Schmidt S, et al. Mindfulness-based stress reduction and health benefits: A meta-analysis. Journal of Psychosomatic Research. 2004; 57(1): 35-43. http://dx.doi.org/10.10 16/S0022-3999(03) 00573-7

[50] Irving JA, Dobkin PL, Park J. Cultivating mindfulness in health care professionals: A review of empirical studies of mindfulness-based stress reduction (MBSR). Complementary Therapies in Clinical Practice. 2009; 15(2): 61-6. PMid:19341981 http://dx.doi .org/10. 1016/j.ctcp. 2009.01.002

[51] Heard PL, Hartman S, Bushardt SC. Rekindling the flame: Using mindfulness to end nursing burnout. Nursing Management. 2013; 44(11): 24-9. PMid:24157802 http://dx . doi .org/10.1097/01. NUMA . 0000436366.99397 .10

[52] Mackenzie CS, Poulin PA, Seidman-Carlson R. A brief mindfulnessbased stress reduction intervention for nurses and nurse aides. Applied Nursing Research. 2006; 19(2): 105-9. PMid:16728295 http: //dx.doi.org/10.1016/j.apnr.2005.08.002

[53] Richards KC, Campenni CE, Muse-Burke JL. Self-care and wellbeing in mental health professionals: The mediating effects of selfawareness and mindfulness. Journal of Mental Health Counseling. 2010; 32(3): 247-64.

[54] Vago DR, Silbersweig DA. Self-awareness, self-regulation, and selftranscendence (S-ART): A framework for understanding the neurobiological mechanisms of mindfulness. Frontiers in Human Neuroscience. 2012; 6: 296. http://dx.doi.org/10.3389/fnhum.2 012.00296 
[55] Beddoe AE, Murphy SO. Does mindfulness decrease stress and foster empathy among nursing students? Journal of Nursing Education 2004; 43(7): 305-12. PMid:15303583

[56] Christopher JC, Christopher SE, Dunnagan T, et al. Teaching selfcare through mindfulness practices: The application of yoga, meditation, and qigong to counselor training. Journal of Humanistic Psychology. 2006; 46(4): 494-509. http://dx.doi.org/10.11 $77 / 0022167806290215$

[57] Goleman D. Emotional intelligence. New York: Bantam Books; 1995.

[58] Schutte NS, Malouff JM. Emotional intelligence mediates the relationship between mindfulness and subjective well-being. Personality and Individual Differences. 2011; 50(7): 1116-9. http: //dx.doi.org/10.1016/j.paid.2011.01.037

[59] Heffernan M, Quinn Griffin MT, McNulty SR, et al. Self-compassion and emotional intelligence in nurses. International Journal of Nursing Practice. 2010; 16(4): 366-73. PMid:20649668 http://dx.doi.o $\mathrm{rg} / 10.1111 / \mathrm{j} \cdot 1440-172 \mathrm{X} .2010 .01853 . \mathrm{x}$

[60] Aikens KA, Astin J, Pelletier KR, et al. Mindfulness goes to work: Impact of an online workplace intervention. Journal of Occupational and Environmental Medicine. 2014; 56(7): 721-31. PMid:24988100 http://dx.doi.org/10.1097/J0M.0000000000000209

[61] Fortney L, Luchterhand C, Zakletskaia L, et al. Abbreviated mindfulness intervention for job satisfaction, quality of life, and compassion in primary care clinicians: A pilot study. Annals of Family Medicine. 2013 Sep-Oct; 11(5): 412-20. PMid:24019272 http: //dx.doi.org/10.1370/afm.1511

[62] McCann CM, Beddoe E, McCormick K, et al. Resilience in the health professions: A review of recent literature. International Journal of Wellbeing. 2013; 3(1): 60-81. http://dx.doi.org/10.5502/i jw.v3i1. 4

[63] Jackson D, Firtko A, Edenborough M. Personal resilience as a strategy for surviving and thriving in the face of workplace adversity: A literature review. Journal of Advanced Nursing. 2007; 60(1): 19. PMid:17824934 http://dx.doi.org/10.1111/j.1365-264 8.2007.04412.x

[64] Agaibi C, Wilson J. Trauma, PTSD, and resilience: A review of the literature. Trauma Violence Abuse. 2005; 6(3): 195 216. PMid:16237155 http://dx.doi .org/10.1177/152483800 5277438

[65] Lim J, Hepworth J, Bogossian F. A qualitative analysis of stress, uplifts and coping in the personal and professional lives of Singaporean nurses. Journal of Advanced Nursing. 2011; 67(5): 102233. PMid:21261697 http://dx.doi.org/10.1111/j.1365-2 648.2010.05572.x

[66] Achor S. The happiness advantage: the seven principles of positive psychology that fuel success and performance at work. New York: Broadway Books; 2010.

[67] Haidt J. The happiness hypothesis: finding modern truth in ancient wisdom. New York: Basic Books; 2006.

[68] Wiseman R. 59 seconds: think a little, change a lot. New York: Alfred A. Knopf; 2009.

[69] Lyubomirsky S, Layous K. How do simple positive activities increase well-being? Current Directions in Psychological Science. 2013; 22(1): 57-62. http://dx.doi.org/10.1177/096372141 2469809
[70] Fredrickson BL, Mancuso RA, Branigan C, et al. The undoing effect of positive emotions. Motivation and Emotion. 2000; 24(4): 237-58 http://dx.doi.org/10.1023/A : 1010796329158

[71] Fredrickson BL. Positive emotions broaden and build. Advances in Experimental Social Psychology. 2013; 47: 1-53. http://dx.doi . org/10.1016/B978-0-12-407236-7.00001-2

[72] Emmons RA, McCullough ME. Counting blessings versus burdens: An experimental investigation of gratitude and subjective well-being in daily life. Journal of Personality and Social Psychology. 2003; 84(2): 377. PMid:12585811 http://dx.doi.org/10.1037/002 2-3514.84.2.377

[73] Sheldon KM, Lyubomirsky S. How to increase and sustain positive emotion: The effects of expressing gratitude and visualizing best possible selves. Journal of Positive Psychology. 2006; 1(2): 73-82. http://dx.doi.org/10.1080/17439760500510676

[74] Post SG. Altruism, happiness, and health: It's good to be good. International Journal of Behavioral Medicine. 2005; 12(2): 6677. PMid:15901215 http://dx.doi.org/10.1207/s15327558 i jbm1202_4

[75] Lyubomirsky S, Sheldon KM, Schkade D. Pursuing happiness: The architecture of sustainable change. Review of General Psychology. 2005; 9(2): 111. http://dx.doi.org/10.1037/1089-2680.9. 2.111

[76] Arnsten AF. Stress signalling pathways that impair prefrontal cortex structure and function. Nature Reviews Neuroscience. 2009; 10(6): 410-22. PMid:19455173 http://dx.doi.org/10.1038/n rn2648

[77] Community Resiliency Model. 2015. Available from: http: //comm unityresiliencymodel.com/ See also Trauma Resiliency Model 2015. Available from: http://traumaresourceinstitute.co $\mathrm{m} /$ trauma-resiliency-model-trm/

[78] Lepore SJ, Smyth JM. The writing cure: how expressive writing promotes health and emotional well-being. Washington, D.C. American Psychological Association; 2002. http://dx.doi.org/10.1037 /10451-000

[79] Halifax J. GRACE for nurses: Cultivating compassion in nurse/patient interactions. Journal of Nursing Education and Practice. 2014; 4(1): 121-128. http://dx.doi.org/10.5430/jnep.v4n1 p121

[80] Maslach C, Jackson SE, Leiter MP. Maslach burnout inventory. Evaluating stress: A book of resources. 1997; 3: 191-218.

[81] Leiter MP. Six areas of worklife: A model of the organizational context of burnout. Journal of Health and Human Services Administration. 1999; 21(4): 472-89. PMid:10621016

[82] Li B, Bruyneel L, Sermeus W, et al. Group-level impact of work environment dimensions on burnout experiences among nurses: A multivariate multilevel probit model. International Journal of Nursing Studies. 2013; 50(2): 281-91. PMid:22831971 http://dx.doi.o rg/10.1016/j.ijnurstu.2012.07.001

[83] Jameton A. Nursing practice: The ethical issues. Prentice Hall; 1984. PMid:10265936

[84] Epstein EG, Delgado S. Understanding and Addressing Moral Distress. Online Journal of Nursing Issues. 2010; 15(3): 1.

[85] American Association of Critical-Care Nurses. The 4 A's to rise above moral distress. Aliso Viejo, CA: American Association of Critical-Care Nurses. 2004. 